\title{
PERANAN PARTI KEADILAN SEJAHTERA (PKS) DALAM SEKTOR MUAMALAT INDONESIA
}

\author{
Ardiansyah Ashri Husein \\ Suhaili Sarif
}

\begin{abstract}
Muamalat or Islamic banking is a rapidly growing sector in Indonesia. The development of this sector is triggered by the movement of societies and political parties mainly due to the lack of support from the government. One of the parties that played major roles in the development of this sector is the Parti Keadilan Sejahtera (PKS). Before the independence of Indonesia, many NGO leaders and political parties have tried to introduce and develop the field of Islamic economy. PKS continued to play a role to reinforce this field during the post-economic collapse at the end of the 1990s. Among the roles played by PKS include introducing the micro financial agency or commonly known as Baitul Mal Wa Tamwil (BMT), engaging in the establishment of Bank Syariah along with Majelis Ulama Indonesia (MUI), establishing Islamic economy studies institution and fighting for laws regarding muamalat.
\end{abstract}

\section{Pengenalan}

Sejak tahun 2000 selepas tertubuhnya Bank Muamalat dan Bank Syariah, muamalat atau perekonomian Islam menjadi sektor yang semakin berkembang di Indonesia. Bank-bank ini tidak lagi hanya sebagai pilihan alternatif, tetapi sudah menjadi sebahagian daripada industri perbankan di Indonesia yang ikut berperanan dalam meningkatkan kesejahteraan masyarakat. Ia juga memperlihatkan perkembangan pesat sektor muamalat meskipun dalam usia yang masih muda jika dibandingkan dengan perbankan konvensional.

Pada peringkat awal, perkembangan muamalat atau ekonomi Islam di Indonesia adalah lahir dari sokongan masyarakat kerana kerajaan Indonesia kurang berminat. Ia merupakan usaha murni individu-individu, institusi dan parti-parti Islam yang prihatin terhadap perkembangan ekonomi masyarakat yang pada ketika itu di bawah kongkongan ekonomi liberal dan sekular. Berbeza dengan negara-negara majoriti Muslim seperti Malaysia, pemerintah Indonesia tidak begitu yakin dan percaya dengan potensi produk-produk Islam. Industri kewangan Islam tidak begitu mendapat sambutan dan dokongan pemerintah. Pemerintah juga tidak memperuntukkan belajawan untuk memperkembangkan sektor muamalat seperti untuk memperkenalkan instrumen-instrumen syariah, program kesedaran sosial dan pendidikan kepada masyarakat. Hal ini seperti dinyatakan oleh Direktur Berita Satu Media Holdings Primus Dorimulu. ${ }^{1}$ Sebenarnya industri kewangan Islam di Indonesia memiliki potensi yang luar biasa. Sehingga pertengahan tahun 2012 sahaja, jumlah aset industri kewangan Islam mencecah Rp285 trillion (lebih kurang RM 8 billion). Hal ini diungkapkan oleh Direktor Eksekutif Perbankan Syariah Bank Indonesia (BI), Edy Setiadi dan Ketua Dewan Syariah Nasional, Majlis Ulama Indonesia (DSN-MUI), Kiyai Haji $(\mathrm{KH})$ Maruf Amin ketika menyampaikan pidato pada acara Anugerah Best Syariah 2012 majalah lnvestor Jakarta, pada 8 Ogos 2012). ${ }^{2}$

Dengan jumlah penduduk beragama Islam mencecah 210 juta, iaitu 88,22 \% dari total keseluruhan rakyatnya yang meletakkan Indonesia sebagai negara muslim terbesar di dunia, sudah selayaknya Indonesia menjadi pelopor dan kiblat pengembangan Muamalat dan Kewangan Islam di dunia. Hal ini bukanlah sesuatu yang mustahil kerana potensi Indonesia untuk menjadi global player muamalat Islam adalah sangat besar kerana mempunyai jumlah penduduk muslim yang besar dan prospek ekonomi yang cerah dengan 
pertumbuhan ekonomi yang relatif tinggi (antara 6.0\%-6.5\%) serta disokong oleh fundamental ekonomi yang kukuh. Oleh yang demikian, kertas kerja ini keseluruhannya akan membincangkan berkenaan perkembangan sektor muamalat di Indonesia serta peranan dan sumbangan institusi bukan kerajaan dalam hal ini.

\section{NGO dan Parti Politik Pemangkin Perkembangan Sektor Muamalat di Indonesia}

Meskipun sektor muamalat sudah mula muncul sekitar 1990-an, perkembangannya tidak memberangsangkan. Pemahaman masyarakat Indonesia pada amnya masih menganggap Islam itu tidak mengatur perkara-perkara dunia, termasuk aktiviti ekonomi. Justeru itu, tidak sedikit orang Islam yang khuatir dan anti terhadap nilai-nilai dan ajaran Islam.

Sebelum kemerdekaan Indonesia pada tahun 1945, memang ada beberapa usaha sejumlah tokoh, institusi, dan parti untuk memperkenalkan sistem ekonomi Islam kepada masyarakat Indonesia. Tetapi usaha tersebut gagal kerana keadaan ekonomi rakyat yang tidak stabil dan masalah dalaman organisasi. Salah satu organisasi yang cukup terkenal pada masa itu adalah Sarekat Islam (SI) yang merupakan organisasi yang lahir dari Sarekat Dagang Islam (SDI). SI merupakan organisasi yang memiliki agenda ekonomi dan politik. Organisasi berskala nasional dan moden ini menuntut pemerintahan oleh rakyat tempatan serta menuntut kemerdekaan daripada Belanda. Tujuan lainnya adalah membangkitkan semangat keusahawanan pribumi (anak tempatan) dan membangun kerjasama untuk melawan pedagang asing yang mendapat layanan istimewa dari penjajah Belanda.

Organisasi SDI pada mulanya merupakan perkumpulan pedagang-pedagang Islam. Organisasi ini dirintis oleh Hj. Samanhudi di Surakarta pada 16 Oktober 1905,, dengan matlamat utama adalah menghimpunkan para pedagang pribumi Muslim (khususnya pedagang batik) agar dapat bersaing dengan pedagang-pedagang besar Cina. Pada saat itu, pedagang-pedagang Cina telah lebih maju dan memiliki hak yang lebih tinggi daripada penduduk Hindia Belanda lainnya. Polisi yang sengaja dibuat oleh pemerintah Belanda tersebut kemudian menimbulkan perubahan sosial kerana timbulnya kesedaran di kalangan warga pribumi yang biasa disebut sebagai Inlanders.

SDI adalah organisasi ekonomi yang berasaskan Islam dan perekonomian rakyat. Ia berkembang pesat sehingga menjadi perkumpulan yang berpengaruh. R.M. Tirtoadisurjo pada tahun 1909 mendirikan Sarekat Dagang Islamiyah di Batavia. Pada tahun 1910, Tirtoadisuryo mendirikan lagi organisasi yang sama di Buitenzorg. Demikian pula, di Surabaya Hj. Oemar Said Tjokroaminoto mendirikan organisasi serupa pada tahun 1912. Hj. Oemar Said Tjokroaminoto menganggotai SDI bersama Hasan Ali Surati, seorang berketurunan India, yang kemudian memegang kewangan surat khabar SDI, Oetusan Hindia. Hj. Oemar Said Tjokroaminoto kemudian dilantik menjadi pengerusi SDI, dan mengubah nama SDI menjadi Sarekat Islam (SI). Hal ini dilakukan agar organisasi ini tidak hanya bergerak dalam bidang ekonomi, tapi juga dalam bidang lain seperti politik.

Seiring dengan perubahan waktu, selepas pemerintah membenarkan berdirinya parti politik, SI berubah menjadi parti politik dan mengirimkan wakilnya ke Volksraad (semacam dewan rakyat) pada tahun 1917, iaitu Hj. Oemar Said sendiri. ${ }^{4}$ Dari sini kemudian peranan parti ini semakin dirasakan oleh rakyat, terutama dalam meningkatkan taraf hidup rakyat, dan memperkenalkan sistem ekonomi berasaskan Syariah seperti memperkenalkan sistem koperasi Islam. Walau bagaimanapun, pada masa ini sistem perekonomian Islam dan penerapannya dalam masyarakat tidak begitu berjaya kerana kondisi rakyat yang masih dijajah oleh Belanda dan pemahaman Islam yang belum menyeluruh di Indonesia.

Kemuncak perkembangan perekonomian Islam di Indonesia hanya dapat dirasai pada hujung 1990-an apabila negara dilanda krisis ekonomi yang teruk sehingga terjadinya reformasi besar-besaran ke atas kepimpinan Presiden Soeharto lalu digantikan oleh Bj. Habibi selaku pemangku naib presiden ketika itu. Dengan terjadinya peralihan kuasa 
tersebut, parti-parti baru dari kalangan umat Islam yang dahulunya agak tertekan telah tumbuh dengan banyak, antaranya ialah Parti Keadilan (PK) 1998 yang selanjutnya berganti nama menjadi Parti Keadilan Sejahtera (PKS) 2003.

Jika pada zaman penjajah Belanda, Non-Government Organization (NGO) dan ulama Islam memberi peranan amat signifikan dalam mengembangkan sektor muamalat Islam. Pada era reformasi Indonesia, NGO juga turut sama menyumbangkan peranan dan buah pemikiran. Salah satunya adalah gerakan tarbiyah yang kemudian bertukar nama menjadi PKS. Sebelum menubuhkan parti, aktivis parti tersebut telah bergerak dalam institusi dan NGO Islam yang sudah ada semenjak tahun 1980-an. Pelbagai pencapaian dalam bidang sosial dan pendidikan telah disumbangkan kepada rakyat Indonesia. Justeru, mereka juga cukup berperanan dalam perkembangan sektor muamalat di Indonesia, sama ada peranan individu berupa sejumlah pakar ekonomi dan bank syariah, ataupun peranan institusi, NGO yang memberi sumbangan positif terhadap perkembangan sektor muamalat di Indonesia. Di antara sumbangan besar ahli-ahli PKS bagi bangsa Indonesia dalam sektor muamalat adalah penubuhan Baitul Mal Wa Tamwil (BMT), ianya merupakan benih pertama bertumbuhnya koperasi moden atau Bank Muamalat Islam pada hari ini.

Secara umumnya, muamalat atau perekonomian Islam di Indonesia tidak berkembang dengan usaha mantap oleh kerajaan tetapi dicetuskan oleh gerakan NGO atau parti politik berasaskan Islam terutamanya PKS. Seperti yang akan dibuktikan nanti, PKS telah mencetuskan perkembangan sistem perekonomian Islam di Indonesia melalui pelbagai inisiatif organisasi tersebut.

\section{PKS Sebagai NGO Masyarakat dan Parti Modernis Islam}

PKS adalah organisasi NGO yang multidinamik. Dalam merealisasikan agenda-agenda ini, PKS menggunakan dua cara; yang pertama melalui peranannya sebagai organisasi masyarakat yang memang telah wujud sebelum ianya menjadi sebuah parti dan yang kedua peranannya sebagai parti politik di parlimen. ${ }^{5}$

PKS juga adalah parti yang peduli terhadap keadaan masyarakat, bukan hanya menjelang pilihan raya. Ketika masyarakat dilanda bencana, PKS berada dihadapan untuk membantu masyarakat. Tsunami di Aceh, gempa bumi di Yogyakarta, bencana gunung berapi di Sleman, banjir di Jakarta, dan daerah lain telah mendapat perhatian PKS. Tidak berlebihan jika sumbangan PKS pernah diungkapkan di TV One, "PKS selalu di hadapan ketika negeri ini memerlukan pertolongan".

PKS bercita-cita memperjuangkan Islam sebagai jalan penyelesaian dalam kehidupan berbangsa dan bernegara. Ia diharapkan berfungsi sebagai kekuatan yang mempelopori dan menggalang kerjasama dengan pelbagai kekuatan dalam menegakkan nilai dan sistem Islam. PKS juga bercita-cita untuk mewujudkan masyarakat madani yang adil, sejahtera, dan bermartabat.

Masyarakat Madani adalah masyarakat berperadaban tinggi dan maju berdasarkan nilai-nilai, norma, hukum, moral yang disandarkan kepada keimanan; menghormati kepelbagaian; bersikap terbuka dan demokratik; dan bergotong royong menjadi kedaulatan negara iaitu dengan merealisasikan ukhuwwah Islamiyyah (ikatan keIslaman), ukhuwwah wataniyah (ikatan kebangsaan), serta ukhuwwah basyariyyah (ikatan kemanusiaan) dalam kerangka Negara Kesatuan Republik Indonesia (NKRI). Adil ialah satu keadaan apabila entiti dan kualiti kehidupan sama ada dalam pembangunan politik, ekonomi, hukum dan sosial budaya ditempatkan secara seimbang serta tidak melampaui batas.

Sejahtera pula mengarahkan pembangunan material dan spiritual manusia agar dapat berperanan sebagai hamba dan khalifah Allah secara seimbang. Oleh itu, kesejahteraan adalah keseimangan (tawazun) hidup yang merupakan buah dari kemampuan seseorang memenuhi tuntutan-tuntutan dasar seluruh dimensi dirinya (ruh, akal dan jasad). 
Bermartabat, secara individu dan sosial menuntut bangsa Indonesia yang menempatkan dirinya sejajar dengan bangsa-bangsa lain di dunia. PKS berhasrat Indonesia menjadi negara kuat yang membawa misi rahmat keadilan bagi segenap umat manusia, agar bangsanya menjadi penyumbang peradaban manusia dan buminya menjelma menjadi taman kehidupan yang tenteram dan damai. ${ }^{6}$ PKS juga, dalam Pasal 3 Anggaran Rumah Tangga PKS disebutkan tujuan parti adalah sebagai berikut:

a. Menyampaikan dakwah dan tarbiyah Islamiyah kepada masyarakat, khususnya umat Islam, secara benar, jelas, sempurna dan menyeluruh.

b. Mendorong kebajikan di pelbagai bidang kehidupan.

c. Membanteras kebodohan, kemiskinan dan kerosakan moral.

d. Menghimpun jiwa dan menyatukan hati manusia di bawah naungan prinsip-prinsip kebenaran.

e. Mendekatkan pelbagai persepsi antara mazhab-mazhab di kalangan umat Islam.

f. Memberi alternatif solusi terhadap pelbagai persoalan umat dan bangsa serta pembangunannya.

g. Membangun peradaban manusia atas dasar keseimbangan iman dan materi.

h. Meningkatkan kesejahteraan ahli parti dan masyarakat.

i. Mengembangkan dan melindungi kekayaan bangsa dan negara.

j. Memajukan perlindungan hak-hak asasi manusia. ${ }^{7}$

Berdasarkan kenyataan di atas kita dapat mengatakan bahawa parti ini merupakan NGO yang memiliki satu cita-cita suci iaitu untuk meningkatkan taraf hidup dan kesejahteraan masyarakat Indonesia. Menurut PKS, Ekonomi Syariah harus mendapat tempat yang signifikan dalam proses pembangunan ekonomi nasional. PKS melihat ekonomi Islam mampu memberikan sumbangan yang strategik dalam menyelesaikan permasalahan ekonomi nasional.

Selain sebagai NGO yang aktif, PKS juga merupakan parti politik berasaskan agama yang berwibawa. PKS pada awalnya bernama Parti Keadilan, namun kemudian berubah menjadi Parti Keadilan Sejahtera (PKS), pada Pilihan Raya Umum (PRU) 1999 menang hanya tujuh kerusi parlimen, dan pada PRU 2004 menang 45 kerusi parlimen, malahan menang di Jakarta dan beberapa bandar utama di Indonesia. Meskipun masih baru, PKS telah mengatasi parti Islam lain, seperti Parti Kebangkitan Bangsa (PKB), Parti Persatuan Pembangunan (PPP), Parti Bulan Bintang (PBB), dan Parti Amanat Nasional (PAN).

Hasil kajian terakhir Lingkaran Survey Indonesia (LSI) pada awal Oktober 2012 lalu mendapati sokongan terhadap parti-parti Islam di Indonesia tidak begitu memberangsangkan berbanding parti-parti sekular dan nasionalis. Paling diminati rakyat adalah Parti Golkar 21\%, Parti Demokrasi Indonesia-Perjuangan (PDI-P) 17.2\%, Parti Demokrat 14\%, Parti Gerakan Indonesia Raya (Gerindra) 5.2\% dan Parti Nasional Demokrat (Nas Dem) 5\%. Sebaliknya parti-parti Islam seperti Parti Persatuan Pembangunan (PPP), Parti Kebangkitan Bangsa (PKB) dan parti-parti yang berlatarbelakangkan Islam dijangka akan terhapus kerana berada dibawah 5\%.8 Walau bagaimanapun, PKS tetap mendapat sokongan padu dari masyarakat. Sokongan padu rakyat ini dapat dilihat pada setiap Pilihan Raya Umum (PRU) dan Pilihan Raya Kecil (PRK) di sejumlah daerah di Indonesia. PKS meraih undi yang sangat membanggakan. Bahkan, sejumlah tinjauan mendapati PKS selalu berada di tempat ketiga teratas. Hasil tinjauan Majalah Kompas menunjukkan bahawa PKS merupakan parti yang kukuh dan memiliki visi jelas dan selalu menjadi pembicaraan di tengah masyarakat. ${ }^{9}$

PKS juga sebuah organisasi yang menarik untuk dikaji. Sebagai parti Islam yang baru pasca reformasi, parti ini diasaskan oleh generasi muda dan golongan berpelajaran tinggi, justeru sebahagiaan besar pemimpin atasan parti ini adalah lulusan sarjana dan PhD dalam 
pelbagai bidang kepakaran. Ketika ini tidak kurang daripada 300 lulusan PhD, bahkan beberapa individu sudah menjadi profesor muda yang bersedia menjadi pelapis.

Hal sedemikian tidak didapati di kebanyakan parti di Indonesia yang sebahagiaan besarnya dikendalikan oleh generasi yang telah berusia dan hanya lepasan sarjana muda sahaja atau tidak sempat menyelesaikan pengajian di mana-mana institusi pendidikan. Di Indonesia, generasi muda dikenali dengan barisan aktivis Muslim Indonesia berumur antara 25 hingga 40 tahun. Parti ini juga diminati oleh golongan remaja di bandar-bandar besar Indonesia, seperti Jakarta, Bandung danYogyakarta.

Sejak awal penubuhannya, PKS juga komited untuk menjaga perilaku politiknya supaya tetap bersih dari rasuah dan nepotisme. Walaupun sejumlah anggota legislatif telah didapati terjerat kes rasuah, PKS mampu membuktikan ia sebagai parti yang bersih dengan tiada satu pun anggota legislatifnya terlibat dalam kes-kes salah laku.

Kenyataan ini membuktikan dua hal sekali gus. Pertama, anggota legislatif PKS adalah mereka yang memiliki integriti serta komitmen yang baik. Mereka menjadi anggota legislatif bukan kerana motif peribadi tetapi kerana tanggung jawab terhadap umat. Kedua, PKS memiliki sistem yang kuat dan baik untuk menjaga dan mengawal kader-kadernya agar tidak menyimpang.

Kebanyakan parti politik di Indonesia termasuk parti Islam mempunyai orientasi kekuasaan semata-mata. PKS justeru menampilkan satu tradisi baru dalam politik Indonesia, iaitu parti dakwah dan menguatkuasakan undang-undang Islam dalam kehidupan dan bernegara yang sememangnya pernah dilakukan oleh Rasulullah semasa membangunkan kota Madinah Al-Munawwarah.

\section{Sumbangan PKS Dalam Perkembangan Sektor Muamalat di Indonesia}

Maksud sektor muamalat dalam artikel ini adalah bentuk atau bidang-bidang garapan muamalat itu sendiri, seperti Perbankan Islam, Takaful, Pemberdayaan Zakat dan Wakaf, Faraid, dan lain-lain. Di Indonesia, muamalat adalah sinonim dengan ekonomi Islam atau ekonomi Syariah.

Berbicara tentang perkembangan sektor muamalat di Indonesia maka kita akan berbicara tentang perkembagan ekonomi Islam atau ekonomi Syariah di negara tersebut. Sebelum 1980, sistem ekonomi yang dijalankan di Indonesia adalah sistem sekular. Sistem ekonomi sekular ini ini telah dipraktikkan berabad-abad lamanya bukan sahaja oleh orang bukan Islam tetapi juga oleh umat Islam sendiri. ${ }^{10}$ Keadaan seperti ini tentu saja tidak terlepas dari modenisasi peradaban sekular barat yang dipengaruhi oleh teori ekonomi liberal, kapitalisme, sosialisme, modenisme, dan lain-lain. Dari semasa ke semasa PKS telah berperanan dalam perkembangan sektor muamalat melalui beberapa kes berikut.

\section{Memperkenalkan Ekonomi Islam dan Menubuhkan Bank Syariah Indonesia}

Pada mulanya, perkembangan ekonomi Syariah di Indonesia ditandai dengan penubuhan bank yang berlandaskan Syariah iaitu Bank Muamalat pada tahun 1990 namun pelaksanaannya hanya pada tahun 1991. Bank Muamalat adalah Bank Syariah pertama di Indonesia yang tidak berdasarkan sistem faedah (interest), tetapi berlandaskan perkongsian keuntungan dan kerugian. ${ }^{11}$ Ahli-ahli PKS adalah antara yang awal mendorong tercetusnya sistem ekonomi Islam dan menggesa penubuhan institusi kewangan berlandaskan syariah. Ahli-Ahli PKS yang sedang menuntut di Institut Teknologi Bandung (ITB) telah memulakan aktiviti ekonomi dengan prinsip-prinsip syariah dengan menubuhkan institusi kewangan dan pembiayaan seakan-akan Baitul Mal wa Tamwil (institut pembiayaan kredit Islam) pada tahun $1984 . .^{12}$

Melalui dua organisasi Islam yang cukup berpengaruh waktu itu, iaitu Ikatan Cendekiawan Muslim Indonesia (ICMI) dan Majlis Ulama Indonesia (MUI), ahli-ahli dan 
simpatisan PKS memberikan idea-idea bijak berkaitan penubuhan Bank Muamalat dan menggesa pemerintah untuk membuat rancangan undang-undang yang mengatur Perbankan Islam. Di antara ahli dan tokoh PKS yang terlibat dalam usaha ini adalah Dr. Muhammad Syafi'i Antonio, Prof. Dr. Didin Hafiduddin, Prof. Dr. Ir. M. Amin Azis. Dr. Muhammad Syafi'i Antonio juga termasuk orang pertama yang dilantik menguruskan Bank Muamalat Indonesia. Pada masa itu, ketiga tokoh ini dijadikan rujukan utama dalam diskusi-diskusi penting tentang ekonomi Islam atau ekonomi Syariah.13

Pada Ogos 1990, Majlis Ulama Indonesia (MUI) mengadakan Seminar Bunga Bank dan Perbankan di Cisarua, Bogor, Jawa Barat. Hasil seminar tersebut dibahas lebih mendalam pada Mesyuarat Nasional IV MUI yang dilaksanakan di Syahid Jaya Hotel pada tahun yang sama. Berdasarkan amanat Mesyuarat MUI, dilantik satu kumpulan untuk menubuhkan Bank Muamalat Indonesia. ${ }^{14}$

Selanjutnya pada tanggal 1 November 1991, kumpulan ini berhasil mendirikan Bank Muamalat Indonesia (BMI) yang mula beroperasi sejak September 1992. Pada awalnya, kehadiran BMI tidak mendapat perhatian baik dari pemerintah mahupun industri perbankan. Namun dalam perkembangannya, ketika BMI dapat kekal beroperasi walaupun ketika krisis ekonomi tahun 1997, telah memberi kesedaran kepada pemerintah untuk memberikan perhatian kepada perbankan Islam, serta menggalakkan penubuhan bank-bank syariah lain baik dalam bentuk Bank Perkreditan Rakyat Syariah (BPRS) maupun Window Sharia untuk bank umum. ${ }^{15}$

Kewujudan Bank Syariah ini adalah penanda baru dalam aktiviti ekonomi Islam di Indonesia. Bank Syariah adalah bank yang melaksanakan seluruh kegiatannya berdasarkan prinsip-prinsip Syariah dan tidak mengamalkan sistem riba. Bank Syariah mempunyai Dewan Pengawas Syariah yang bertugas mengawasi operasi bank agar bersesuaian dengan ketentuan-ketentuan Syariah.

Pada awal penubuhannya, Bank Muamalat Indonesia belum mendapat simpati dan pemerhatian yang optimal dalam industri perbankan Indonesia. Landasan hukum operasi bank yang menggunakan sistem Syariah ini dikategorikan sebagai bank dengan sistem perkongsian hasil sahaja, tidak ada perincian landasan hukumnya serta jenis-jenis usaha yang dibenarkan. Perkara ini seperti termaktub dalam Undang-Undang No. 7 tahun 1992.

Perkembangan Perbankan Syariah pada era reformasi ditandai dengan pengenalan Undang-Undang No. 10 Tahun 1998. Undang-undang tersebut memperincikan landasan hukum serta jenis-jenis usaha yang boleh dioperasikan dan direalisasikan oleh Bank Syariah. Undang-undang tersebut juga memberikan arahan bagi bank-bank konvensional untuk membuka cabang Syariah atau berubah secara total menjadi Bank Syariah. Sehingga Mac 2013, BMI telah mempunyai 79 cawangan di seluruh Indonesia, 158 pejabat cawangan bantuan, dan 121 pejabat kewangan yang ada di seluruh Indonesia. ${ }^{16}$

Secara umum, antara produk-produk Bank Syariah yang telah berjaya diperkenalkan oleh ahli-ahli PKS adalah:

a. Produk Penghimpunan Dana (Funding) yang menggunakan prinsip Wadiah dan Mudarabah.

b. Produk Pembiayaan (Financing) meliputi pembiayaan modal usaha, pembiayaan pelaburan dan pembiayaan konsumtif / kepenggunaan.

c. Produk Jasa seperti Wakalah, Kafalah dan Hawalah.

\section{Memperkenalkan Badan Kewwangan Mikro/Mikro Kredit (Baitul Mal wa Tamwil}

Selepas tertubuhnya Bank Muamalat Indonesia (BMI) peluang untuk menubuhkan bankbank yang berprinsip syariah semakin terbuka. Pengurusan BMI kurang memberikan perhatian kepada perusahaan kecil dan sederhana. Oleh yang demikian, PKS menggesa 
penubuhan bank dan lembaga kewangan mikro, seperti Bank Perumahan Rakyat (BPR) Syariah dan BMT yang bertujuan untuk mengatasi kekurangan dalam beberapa aspek dalam kewangan komersil.

Penubuhan Baitul Mal wa Tamwil (BMT) ini bermula daripada satu diskusi dalam kalangan ahli-ahli PKS tentang kepentingan wujudnya institusi kewangan bukan bank yang boleh membantu perusahaan kecil dan sederhana, serta mengelakkan umat Islam dari menjadi mangsa pemberi hutang, terutama mereka yang miskin dan kekurangan modal. Atas nasihat dan sokongan dari salah seorang ulama Indonesia, Prof. KH Ali Yafie (Ketua Majelis Ulama Indonesia), Baitul Mal Wa Tamwil Insan Kamil (BIK) telah ditubuhkan pada tahun 1992. Rizal Muganegara, alumni akademi kewangan dan perbankan Muhammadiyah, dilantik menjadi pengerusi eksekutif yang pertama. BMT BIK ini merupakan BMT pertama di Indonesia yang menjadi model dalam pengembangan BMT selanjutnya.

Beliau kemudian mulai merintis Pusat inkubator perniagaan, Pusat Inkubasi Bisnis Usaha Kecil (PINBUK) di BMT Propinsi Lampung. Pada 1996 pula BMT Swadaya telah ditubuhkan dengan 30 cawangan. Seterusnya pada tahun 1998 dengan bantuan pemerintah propinsi, 17 BMT lagi telah ditubuhkan. Pelbagai cawangan terus berkembang dari semasa ke semasa seperti BMT As-Syifa di Metro, BMT Mentari di Kota Gajah, BMT Pringsewu, BMT Bagas di Lampung Timur, dan BMT Fajar di Metro. Modal yang disalurkan oleh setiap BMT ini kepada penerima yang layak adalah antara Rp 2 juta (sekitar RM600) dan Rp 5 juta (sekitar RM1,500). ${ }^{17}$

\section{Merancang Undang-Undang Perbankan Syariah dan Memperjuangkannya dalam Parlimen Republik Indonesia}

Secara de jure, sistem perbankan syariah mulai berjalan setelah disahkan Undang-Undang Perbankan No. 7 Tahun 1992 oleh Presiden Soeharto pada 25 Mac 1992. Sebelum tahun 1992 belum ada peraturan perbankan yang secara khusus mengatur perbankan Syariah. Tetapi sayangnya undang-undang ini juga belum secara spesifik menyebut Bank Syariah. Ia hanya menjelaskan makna kredit dan penyediaan dana berdasarkan prinsip Islam sebagai salah satu jenis usaha yang dilakukan, sama ada Bank Awam atau Bank Perkreditan Rakyat. ${ }^{18}$

Kemudian pada tahun 1998 kerajaan Indonesia memperkenalkan Undang-Undang No. 10 Tahun 1998 sebagai pindaan kepada Undang-Undang Perbankan No. 7 Tahun 1992. Ini dibuat atas cadangan Dewan Perwakilan Rakyat Republik Indonesia (DPR-RI). Salah satu fraksi DPR-RI yang memperjuangkan pengesahan Undang-Undang ini adalah Fraksi Parti Keadilan Sejahtera (F-PKS).

Undang-Undang No. 10 Tahun 1998 tentang Perbankan telah menyebut secara jelas perihal Perbankan Syariah. Jika dalam Undang-Undang No. 7 Tahun 1992, Bank Syariah ini disebut dengan istilah 'Bank yang berdasarkan prinsip bagi (perkongsian) hasil', maka dalam Undang-Undang No. 10 Tahun 1998 ini disebut dengan istilah 'Bank berdasarkan prinsip Syariah'. Prinsip syariah yang dimaksudkan dalam Undang-Undang No. 10 Tahun 1998 ini ialah aturan perjanjian berdasarkan hukum Islam antara bank dan pihak lain untuk penyimpanan dana dan atau pembiayaan kegiatan usaha, atau kegiatan lainnya yang dinyatakan sesuai dengan syariah. Antara lain pembiayaan berdasarkan prinsip perkongsian hasil adalah mudarabah, pembiayaan berdasarkan prinsip penyertaan modal (musyarakah), prinsip jual beli barang dengan memperoleh keuntungan (murabahah), atau pembiayaan barang modal berdasarkan prinsip sewa murni tanpa pilihan (ijarah), atau dengan adanya pilihan pemindahan kepemilikan atas barang yang disewa dari pihak bank oleh pihak lain (ijarah wa iqtina). ${ }^{19}$

Untuk memperkukuhkan lagi dasar hukum Perbankan Syariah agar selari dengan prinsip-prinsip al-Quran dan al-Sunnah, serta sesuai dengan keperluan semasa, maka Parti Keadilan Sejahtera bersama dengan parti-parti di DPR-RI merancang sebuah Rancangan 
Undang-Undang (RUU) Tentang Perbankan Syariah. Walaupun ditentang habis-habisan oleh pihak-pihak yang tidak setuju dengan Prinsip-Prinsip Perbankan Syariah, termasuk salah satu parti Kristian di DPR-RI, iaitu Partai Damai Sejahtera (PDS). Melalui juru bicaranya, Retna Rosmanita, Parti Kristian ini secara tegas menolak RUU Perbankan Syariah menjadi Undang-Undang Rasmi di Indonesia. ${ }^{20}$ Ia menyatakan, UU Perbankan Syariah tidak sesuai dengan hukum dasar Pancasila dan Undang-Undang Dasar (UUD) tahun 1945 terutama pasal 27 ayat 1 tentang persamaan hak warganegara dalam perlembagaan. Menurut wakil PDS ini, hal yang berkaitan dengan perbankan telah diatur dalam UU. No. 7 Tahun 1992 tentang Perbankan dan digubal menjadi UU No. 10 Tahun 1998. Oleh itu, tidak perlu lagi undang-undang khusus yang mengatur aktiviti perbankan syariah. Selain itu, RUU Perbankan Syariah disusun berdasarkan agama tertentu, bukan berdasarkan Pancasila.

Elemen Islam amat ketara dalam UU Perbankan Syariah No. 21 Tahun 2008 yang mentakrifkan Bank Syariah sebagai bank yang menjalankan kegiatan usaha berdasarkan prinsip Syariah. ${ }^{21}$ Maksud prinsip Syariah adalah prinsip hukum Islam dalam kegiatan perbankan berdasarkan fatwa yang dikeluarkan oleh lembaga yang memiliki kuasa dalam penetapan fatwa di bidang Syariah. Lembaga fatwa yang dimaksudkan ialah Majlis Ulama Indonesia (MUI).

\section{Menubuhkan Institusi Pengajian di Bidang Ekonomi Islam dan Muamalat}

Sistem syariah yang bagus tidak akan bermakna apabila tidak diperkuat dengan sumber manusia yang mengerti selok-belok kewangan Islam, yang akan menguruskan institusiinstitusi tersebut. Ahli-ahli PKS adalah yang terawal berbicara tentang kepentingan penubuhan institusi pengajian tinggi yang menawarkan program ekonomi Islam. PKS melihat pertumbuhan institusi kewangan syariah tentu memerlukan sokongan sumber manusia yang pakar bukan sahaja memiliki kepakaran dalam bidang sains dan teknologi tapi juga mendalam tentang aspek-aspek syariah.

Antara institusi pengajian tinggi yang ditubuhkan oleh ahli-ahli PKS ialah Sekolah Tinggi Ekonomi Islam SEBI (STEI SEBI) iaitu institusi pendidikan yang ditubuhkan oleh ahli-ahli PKS melalui Yayasan Bina Tsaqofah. ${ }^{22}$ Institusi ini dipimpin oleh Prof. Dr. Didin Hafiduddin yang merupakan ahli PKS dan pernah dipilih menjadi calon Presiden Republik Indonesia mewakili PKS sewaktu masih bernama Parti Keadilan. Ada dua program pengajian yang ditawarkan di STEI SEBI yang berhubungan dengan Ekonomi Syariah iaitu Perbankan Syariah dan Akutansi Syariah (Perakaunan Islam). Kedua-dua program ini berperanan penting dalam perkembangan ilmu ekonomi syariah di Indonesia. STEI SEBI merupakan kampus yang progresif, dianggotai oleh pakar dan ahli akademik yang kompeten dalam ekonomi dan kewangan syariah.

Institusi pengajian tinggi lain yang ditubuhkan oleh ahli PKS ialah Sekolah Tinggi Ekonomi Islam (STEI) TAZKIA / TAZKIA University College of Islamic Economics. Peranan Tazkia dalam pengembangan ekonomi syariah bermula pada awal tahun 1998 ketika Bank Indonesia mula memberikan perhatian terhadap pengembangan perbankan Islam, sebagai salah satu cara untuk memperkuat semula industri perbankan nasional yang runtuh akibat krisis ekonomi. Pada ketika itu, Tazkia diberi kesempatan oleh Bank Indonesia untuk menyelenggarakan kursus berkaitan perbankan syariah, sama ada untuk pegawai dan pekerja industri perbankan nasional. Kesan dari kursus-kursus ini membuahkan hasil yang cukup baik. Bank Indonesia Finance and Investment Company (IFI) yang dahulunya merupakan institusi kewangan konvensional memutuskan untuk mendirikan Unit Usaha Syariah (UUS). Pemegang saham Bank Susila Bhakti (BSB) juga memutuskan untuk menceburi bidang kewangan Islam, lalu ditubuhkan Bank Syariah Mandiri (BSM). Langkah Bank IFI dan BSM tersebut lalu diikuti oleh banyak bank-bank konvensional lain seperti Bank Jabar, Bank Bukopin, Bank Danamon, Bank Jateng, Bank SUMUT, Bank BRI, dan Bank BNI. 


\section{Mengeluarkan Fatwa Berkaitan Ekonomi Islam dan Figh Muamalat}

Sebagai parti dakwah, PKS memberi perhatian serius kepada masalah-masalah yang berlaku di tengah masyarakat, di antaranya masalah-masalah berkaitan muamalat dan kewangan Islam. Parti ini ada mempunyai satu institusi fatwa dan qadha yang disebut 'Dewan Syariah' yang mempunyai tugasan merumuskan landasan syarak bagi parti dan memberi fatwa berkenaan pelbagai persoalan dan permasalahan yang dihadapi oleh ahlinya serta masyarakat umum. Tugas Dewan Syariah seperti mana yang dituliskan dalam anggaran dasar PKS:
a. Sebagai lembaga fatwa.
b. Sebagai lembaga qadha.
c. Yang melaksanakan tugas-tugas khusus yang ditetapkan oleh majlis syura.
d. Majlis syura adalah lembaga tertinggi parti yang berfungsi sebagai lembaga parlimen (Ahlul Halli wa al- Aqdi) Parti Keadilan Sejahtera (PKS).
e. Lembaga peradilan banding. ${ }^{23}$

Di antara fatwa bidang muamalat yang dikeluarkan oleh Dewan Syariah PKS ialah:
a. Bayan berkaitan Zakat Profesi (Profesional).
b. Perniagaan BBA dan sewaan kenderaan.
c. Bay al-Wafa.
d. Pasaran hadapan.
e. Perniagaan dengan kaedah Multi Level Marketing (MLM).
f. Hukum meminjam wang dari bank konvensional yang mengamalkan riba.
g. Biasiswa dari bank konvensional.
h. Riba dan bunga bank.
i. Rasuah dalam Islam. ${ }^{24}$

Selain fatwa di bidang muamalat, Dewan Syariah PKS juga mengeluarkan fatwa-fatwa dalam bidang ibadah, politik, dan permasalahan-permasalahan semasa.

\section{Kesimpulan}

Sebagai negara yang jumlah penduduknya mencecah 230 juta orang, maka kesejahteraan rakyat Indonesia menjadi isu utama yang diperbincangkan. Ianya bukan satu pekerjaan mudah bagi pemerintah untuk mengatasi masalah kemiskinan dan kesejahteraan yang kerap timbul akibat jumlah penduduk yang sebegitu besar. Oleh itu, peranan dan sumbangan NGO dan parti politik yang perihatin terhadap masalah masyarakat amat sangat diperlukan, terutama sekali NGO dan parti politik yang memiliki pandangan Islam yang kaffah, yang melihat Islam tidak hanya dari kaca mata peribadatan semata-mata, tetapi juga mengurus hal-ehwal dunia seperti politik, ekonomi dan budaya.

Sebagai NGO dan kemudian menjadi parti politik, PKS amat besar sumbangannya di Indonesia dalam memangkin sektor muamalat di Indonesia. PKS telah memangkin perkembangan sektor muamalat di Indonesia dengan memperkenalkan Ekonomi Syariah dan menubuhkan Bank Syariah Indonesia. PKS juga telah menggesa penubuhan Baitul Mal wa Tamwil (BMT) iaitu Institusi Kewangan dan Modal (Memperkenalkan Badan Kewangan Mikro/Mikro Kredit), merancang Undang-Undang Perbankan Syariah dan memperjuangkannya di parlimen, menubuhkan institusi pengajian ekonomi Islam dan muamalat serta mengeluarkan fatwa yang berkaitan ekonomi Islam dan fikah muamalat. Usaha PKS ini dijangka akan berterusan dan sentiasa berkembang dari semasa ke semasa. 


\section{Nota}

Lihat “Industri Kewangan Syariah Perlu Dukungan Pemerintah", Investor Daily, Vol. 1, 2012.

Ibid.

N. Notosusanto, Sejarah Nasional Indonesia, Jakarta: Balai Pustaka, 1992, hlm. 23.

Ibid.

C. Takariawan, Menyongsong Mihwar Daulah, Bandung: Era Adicitra Intermedia, 2010, hlm. 15.

6 Majelis Pertimbangan Pusat Parti Keadilan Sejahtera, 2009. Platform Kebijakan Pembangunan dan Falsafah Dasar Perjuangan PKS, Mampang Prapatan Raya Jakarta.

7 Ibid.

8 Hasil survei LSI pada tahun 2012. http:// www.lsi.or.id , diakses pada 14 Oktober 2012.

9 Hasil survei KOMPAS pada tahun 2012. http://www.kompas.com , diakses pada 24 Julai 2012.

10 S. Iska, Sistem Perbankan Syariah di Indonesia dalam Perspektif Fikih Ekonomi, Yogyakarta: Fajar Media Press, 2012, hlm. 14.

11 A.A. Hakim, Figh Perbankan Syariah, Transformasi Figh Muamalah ke dalam Peraturan PerundangUndangan, Bandung: Reflika Aditama, 2011, hlm. 11.

12 M.A. Aziz, Tata Cara Pendirian BMT, Jakarta: PKES Publishing, 2008, hlm. 14.

13 Temubual dengan Akmal Burhanuddin, Pegawai BMI pada 5 September 2013.

14 M.S. Antonio, Bank Syariah: Dari Teori ke Praktek, Jakarta: Gema Insani Press, hlm. 21.

15 S. Iska, Sistem Perbankan Syariah di Indonesia dalam Perspektif Fikih Ekonomi, hlm. 16.

16 Imam Munandar, "Kedudukan BMT (Baitul Mal wa Tamwil) Dalam Lembaga Keuangan di Indonesia". https://munandarbrigd.wordpress.com/kedudukan-bmt-baitul-maal-wat-tamwildalam-lembaga-keuangan-di-indonesia-by-iman-munandar/, diakses pada 14 Oktober 2012.

17 Temubual dengan Akmal Burhanuddin, Pegawai BMI pada 5 September 2013.

18 Undang-Undang No. 7 Tahun 1992 Tentang Perbankan, Pasal 1.

19 Undang-Undang No. 10 Tahun 1998 Tentang Perbankan, Pasal 1, No. 13.

20 A.A. Hakim, Figh Perbankan Syariah, hlm. 12.

21 Undang-Undang No. 21 Tahun 2008 Tentang Perbankan Syariah, Pasal 1, No. 12.

22 http://www.sebi.ac.id/, diakses pada 15 Oktober 2013.

23 Majelis Pertimbangan Pusat Parti Keadilan Sejahtera, 2009. Platform Kebijakan Pembangunan dan Falsafah Dasar Perjuangan PKS, Mampang Prapatan Raya Jakarta.

24 Dewan Syariah Pusat Parti Keadilan Sejahtera, 2005. Fatwa-Fatwa Dewan Syariah Pusat Parti Keadilan Sejahtera, Jakarta. 